\title{
UMA IDENTIDADE MASCARADA: A QUEBRA DE FRONTEIRAS REALIDADE/FICÇÃO NA OBRA EM LIBERDADE DE SILVIANO SANTIAGO
}

\author{
Antonio Roberto Fernandes do Nascimento ${ }^{1}$ \\ José Carlos Redson ${ }^{2}$
}

\begin{abstract}
Resumo: Este trabalho é uma reflexão sobre a obra Em Liberdade de Silviano Santiago e suas implicações frente o processo de construção da identidade em um cenário de pós-modernidade, que questiona o centro e a tradição literária, colocando a identidade dentro de um processo contraditório, mascarado e, por vezes, inconsciente, a partir do conflito entre realidade e ficção, prisão e liberdade, vida e arte.
\end{abstract}

Palavras-chave: Identidade, Em Liberdade, Pós-moderno, realidade, ficção.

Abstract: This work is a reflection on the work In Freedom of Silviano Santiago and its implications for the process of identity construction in a postmodern scenario that questions the center and literary tradition, placing the identity within an adversarial process, masked and sometimes unconscious, from the conflict between reality and fiction, prison and freedom, life and art.

Keywords: Identity, On Liberty, Postmodern, reality, fiction.

"A afirmação da identidade por meio da diferença e da especificidade é uma constante no pensamento pós-moderno [...] O movimento da diferença e da heterogeneidade para a descontinuidade é um elo que pelo menos a retórica da ruptura não demorou a estabelecer à luz das contradições e dos desafios do pós-modernismo" (Linda Hutcheon).

\footnotetext{
1 Graduado em Letras e Especialista em Literatura e Estudos Culturais na UERN. Graduando em Administração Pública e Especialista em Gestão Pública Municipal pela UFRN.Email: arfn_robertom@hotmail.com.

${ }^{2}$ Graduado em Letras e Especialista em Literatura e Estudos Culturais e Mestre em Letras, pela UERN.
} 


\section{INTRODUÇÃO}

Desde o princípio da humanidade o homem vem tentando descobrir o mundo e a si mesmo com seus dilemas e contradições. Entender a si mesmo não é tarefa fácil visto que a sociedade em que está inserido está sempre em constante transformação. Com todas as mudanças que ocorreram ao longo de toda história, o homem tornou-se um ser heterogêneo ocupando um espaço também heterogêneo e assumindo diversas identidades no contexto da vida social e cultural.

A noção de que teríamos uma identidade individual abriu espaço para a multiplicidade dessa identidade baseada na modernização da sociedade que habitamos.

A partir da noção de que a identidade do homem está sempre em construção, o presente ensaio busca investigar sob quais condições é construída a identidade na obra Em liberdade de Silviano Santiago, considerando a quebra das fronteiras realidade e ficção presente no corpo da obra. Para tanto, no sentido de darmos uma contribuição metodológica para nosso trabalho, é preciso fazer um percurso pela pós-modernidade e a manifestação da identidade dentro da literatura brasileira, para só depois disso, construirmos nossas reflexões a partir do tema proposto para o ensaio.

Contudo, é preciso salientar que não pretendemos com isso, apresentar reflexões prontas e acabadas acerca da referida obra, uma vez que o texto literário é capaz de oferecer inúmeras interpretações a seu respeito, desde que essas estejam condizentes com a realidade do texto estudado.

\section{IDENTIDADE E PÓS-MODERNIDADE}

Obviamente, a história de nossa literatura se desenvolve dentro de um complexo processo de afirmação de seus valores. Antes, estava sob o julgo do outro, tímida, acanhada, sentindo-se inferior, estava presa a um centro que impunha a sua autoridade, seu poder e sua influência.

Dessa maneira, nossa arte permaneceu por um longo tempo a mercê da vontade alheia, tendo que suplantar o orgulho e enxergar sua pátria através dos olhos europeus, como sendo um lugar endêmico, exótico, paradisíaco.

Com o passar do tempo, a construção identitária nacional ganhou destaque e pôde representar de forma mais crítica as nossas deficiências do passado, afirmando a relação entre a história e a política, fazendo uma nova leitura de nossas raízes, dos nossos escritos com o intuito não de determinar uma posição pronta e definida, pelo contrário, veio resgatar o passado de forma híbrida, múltipla, provisória e autoconsciente. Dizendo de outro modo, não se trata de acabar com o centro, mas de voltar as atenções para as margens que sempre permaneceram colocadas de lado. Assim,

O centro pode não permanecer, mas ainda é uma atraente ficção de ordem e unidade que a arte e a teoria pós-modernas continuam a explorar e subverter [...] O conceito modernista de uma não identidade única e alienada é desafiado pelo 
questionamento pós-moderno dos binários que ocultam hierarquias [...] A diferença sugere a multiplicidade, a heterogeneidade e a pluralidade, e não a oposição e a exclusão binárias. (HUTCHEON, 1991, 88-89).

Claro está, a partir do exposto acima, que há uma total descentralização de nossas categorias de pensamento com o advento do pós-modernismo. A noção de uma identidade única é colocada à prova no sentido de que, nos vários contextos sociais e culturais, o homem assume diversas identidades que estão sempre em constante construção, ou seja, já não é possível uma identidade pronta e definida, como veremos na obra Em Liberdade de Silviano Santiago.

Com isso, foram grandes e significativas as mudanças e rupturas que aconteceram dentro de nosso sistema literário. O surgimento de narrativas curtas, mas complexas e com a quebra das fronteiras entre a baixa e alta cultura, entre a ficção e a realidade, o indivíduo pós-moderno ganhou um espaço não determinado dentro da esfera social. Já não existem mais fronteiras determinadas em que cada sujeito assume uma função. Assim, é inevitável a heterogeneidade das identidades nas diversas relações exercidas pelo sujeito em sociedade. Em outras palavras,

Quando o centro começa a dar lugar às margens, quando a universalização começa a destruir a si mesma, a complexidade das contradições que existe dentro das convenções começam a ficar visíveis [...] A homogeneização cultural também revela suas rachaduras, mas a heterogeneidade reivindicada como contrapartida a essa cultura totalizante, não assume a forma de um conjunto de sujeitos individuais fixos, mas em vez disso, é concebida como um fluxo de identidades contextualizadas. (Idem, 1991, 86).

Consequentemente observamos que o pós-modernismo pode ser entendido como uma forma de desestabilizar as tradições e colocar as velhas certezas em jogo. Trata-se de repensar uma série de conceitos e não necessariamente negá-los, tornando-se paradoxal e questionador. Nas palavras de Mangadelli $(2005,367)$ : “O pós-modernismo intriga, pois coloca em questão o conceito tradicional que se tem de arte e de suas relações com o mundo. As ideias de um trabalho completo e da existência de certezas acabam e, entramos em um mundo caracterizado pela profissão de fragmentos e incertezas".

Compreende-se com o fim dessas certezas que as reflexões sobre identidade em nossa literatura ganharam outro viés. As identidades, antes já constituídas são questionadas no sentido de que surgiram novas identidades, fragmentando o sujeito pós-moderno.

Com a descentralização dessa identidade, seu próprio conceito passa a ser questionado, uma vez que o sujeito é deslocado da esfera social e cultural. Tudo isso nos leva a observar uma total crise de identidade no sujeito pós-moderno, pois ele se encontra inserido em uma sociedade fragmentada e seus conceitos de tradição estão sempre sendo questionados.

Sobre essa questão da crise de identidade, Hall (2006, 07) afirma que: "A assim chamada 'crise de identidade' é vista como parte de um processo mais amplo de mudança, 
que está deslocando as estruturas e processos centrais das sociedades modernas e abalando os quadros de referência que davam aos indivíduos uma ancoragem estável no mundo social".

O que está em jogo nessa questão é que as sociedades modernas estão sempre em transformação e, com isso, o sujeito adquire novas identidades no processo de vida, de forma que essas mudanças são sempre questionadas de forma perturbadora

A ideia da identidade individual cai por terra, à medida que é preciso compreender o sujeito, que por sua vez, tem sua própria história que vai também se transformando ao longo do tempo, ou seja, sua identidade segue esse ritmo de transformação.

$\mathrm{Na}$ análise que segue da obra Em Liberdade de Silviano Santiago podemos encontrar um sujeito em completo processo de transformação quando resolve através de um diário contar sua vida depois de passar anos preso. O que nos interessa com esse estudo, é descobrir sob quais condições sua identidade é construída, uma vez que as fronteiras realidade/ficção são quebradas de tal forma que, em alguns momentos é quase impossível distingui-las.

\section{ANÁLISE DA OBRA}

Após o verdadeiro impacto causado pelas grandes transformações que aconteceram dentro de nosso sistema literário na pós-modernidade, as obras produzidas pelos autores brasileiros ganharam uma maior complexidade quando se trata de sua real compreensão. Considerando que o texto literário nos permite inúmeras interpretações, é possível estabelecermos uma linha de conexão entre o mundo de uma narrativa ficcional e o mundo que nos cerca.

O que acontece é que muitas vezes não somos capazes de saber em que realidade estamos inseridos ou em qual realidade a obra se enquadra, visto que as fronteiras realidade/ ficção são em alguns casos quebradas pelas novas formas de manifestação literária.

Nessa linha de compreensão podemos citar a obra Em Liberdade de Silviano Santiago, na qual o autor faz uma espécie de pastiche da obra Memórias do Cárcere de Graciliano Ramos. Aqui encontramos um narrador personagem que registra em forma de diário sua vida depois de passar anos numa prisão. O que é interessante observar é que esse narrador se confunde com o personagem, com o próprio narrador e/ou com alguém que conta a vida de Graciliano Ramos ou ainda com o próprio Graciliano.

Claro está que o gênero diário possibilita a quebra de fronteiras entre realidade e ficção, na medida em que apresenta um sujeito individual que não se preocupa com um possível leitor para seu texto, pois o único que possivelmente vá ler um dia seja ele próprio. Existe uma total liberdade de escrita no texto, de forma que o personagem se encontra numa total fase de transição e perturbadora transformação de vida.

No entanto, ele próprio questiona essa liberdade de escrever, como se não soubesse de onde saísse tamanha capacidade de produzi-lo. Logo no início do texto, o narrador parece deixar bem claro o estado de contradição em que se encontra, querendo explicar, talvez a si mesmo, as palavras que lhe saíam quase sem explicação. Vamos à passagem: 
Não sinto o meu corpo. Não quero senti-lo por enquanto. Só permito a mim existir, hoje enquanto consciência de palavras. Estas combinam-se em certas frases que expressam pensamentos meus oriundos da memória afetiva e criados pelo acaso. Combinam-se em outras frases que são respostas a perguntas que me fazem desde que sai ontem da cadeia. Em mais outras frases que traduzem as minhas opiniões sobre isto ou aquilo que leio nos jornais e nas revistas, devorados com avidez. (SANTIAGO, 1985, 27).

Como é possível notar, o narrador parece tentar explicar o porquê de escrever um diário contando sua vida pós-prisão. As palavras saem-lhe sem explicação, ora pra matar a curiosidade dos outros, ora simplesmente de sua própria memória ou até mesmo do acaso. Aqui, já podemos encontrar um sujeito em pleno processo de descobrimento de si mesmo, depois de tanto tempo preso. Veja que ele já não se reconhece, já não sabe mais quem ele é diante da vida que lhe espera do lado de fora da cadeia. Tudo está diferente, inclusive sua forma de ver e pensar as coisas.

$\mathrm{Na}$ verdade, o que temos é um diário escrito por um autor que se encontra subentendido, pois em momento nenhum da obra encontramos o nome desse narrador personagem.

Com esse jogo de contradições, Silviano parece querer mostrar para o leitor que não existe uma linha divisória entre realidade e ficção, pois temos um texto que permanece no meio dessa linha, não nos dando a possibilidade de reconhecer onde a ficção entra e onde encontramos a realidade.

É possível notarmos essa dificuldade logo no título da obra (Em Liberdade: diário de Graciliano Ramos), como se nos quisesse dizer que a obra foi escrita por este escritor brasileiro. Essa ideia pode ser comprovada logo na nota do editor que antecede o texto e está assinada por Silviano em que ele justifica que conseguiu as cópias do diário original com um amigo seu que falecera e havia lhe deixado esse material, mas resolvera publicá-lo respeitando uma condição de Graciliano, como podemos observar no trecho: "Conservei em segredo, até hoje, os originais de Em Liberdade. Resolvo agora publicá-los, obedecendo ao prazo de vinte e cinco anos exigido pelo romancista”. (SANTIAGO, 1985, 13).

O que é particularmente interessante notar é que não existe uma certeza de nada na obra, muito menos distinguir realidade de ficção. O próprio narrador se questiona acerca desse fato, se mostrando confuso no ato de escrever, escondendo sua identidade e assumindo uma postura complexa e contraditória. Nem mesmo ele sabe se o que está fazendo é ficção ou não, como muito bem podemos observar nesta passagem do texto:

[...] Quero acreditar que posso escrever como nunca escrevi. Sei que não posso. A produção das frases está aqui na cabeça, e difícil é passá-las para o papel. O problema não está tanto na dificuldade em transcrevê-las. Basta fechar os olhos e entregar-se no automatismo surrealista da escrita. Encontrar uma razão para a necessidade de deixá-las existir no papel e no livro: eis a questão. Fora de mim e para o outro. Para isso sempre foi preciso "fazer ficção" das minhas palavras. Ou não. (Idem, 1985, 28). 
O fato de o narrador se questionar por que está escrevendo ou para que, nos serve para comprovar a identidade conturbada que este assume no decorrer da obra, visto que não afirma nada e deixa sempre uma dúvida no leitor. É preciso observar que o fazer ficção, a que ele se refere no texto, é colocado entre aspas, como se quisesse mostrar a sua contradição quando está escrevendo. Não se sabe ao certo quem está escrevendo e menos ainda que identidade esse narrador assume diante do texto, pois ele mesmo se questiona acerca disso.

O narrador/personagem parece querer compreender a si mesmo, entender em que estado se encontra diante da nova realidade da sua vida. Vejamos:

Soltar o corpo, rejeitar a adversidade. Buscar a minha identidade em mim, frente a frente, face a face, corpo a corpo. Terei coragem de levantar-me desta escrivaninha, abrir a porta do armário, buscar o espelho e enfrentar a minha imagem refletida, para poder esquecer o passado impresso no corpo e prepará-lo para o futuro? Não me levanto. Ainda não. (p. 32)

De fato, podemos observar que existe de forma implícita certa vontade de enfrentar a sociedade e os dilemas da vida. O narrador/personagem se vê diante de uma contraditória posição acerca de qual identidade está assumindo. O medo, a falta de coragem de se olhar no próprio espelho, reflete a sua angústia diante da vida que lhe espera, uma vez que é ex-presidiário. Aqui, é possível destacarmos que a identidade é construída no processo de relação com o outro em sociedade.

A identidade do possível narrador/personagem agora é outra totalmente diferente daquela que ele tinha antes de ser preso, no entanto, ele precisa entender esse processo de mudança para se entender enquanto ser humano. Para isso, resolve transportar tudo para um diário, texto que ele próprio um dia vai ler. Na concepção de Hall $(2006,38)$ :

A identidade é algo formado, ao longo do tempo, através de processos inconscientes, e não algo inato, existente na consciência no momento do nascimento. Existe sempre algo "imaginário" ou fantasiado sobre sua unidade. Ela permanece sempre incompleta, está sempre "em processo", sempre "sendo formada".

Esta é a sensação que temos quando nos adentramos no texto de Em Liberdade. Existe uma identidade fragmentada, que ainda não foi formada especificamente, mas que se encontra num perfeito estado de contradição no processo de sua formação.

Ainda é possível destacarmos a noção de liberdade que ele tenta buscar, pois o tempo todo ele também se questiona acerca dessa liberdade que está vivendo. Era como se aquela não fosse realmente a liberdade que esperava encontrar fora da prisão. Na verdade, ele precisa aprender a conviver em sociedade, com as novas coisas, pessoas e ambientes que o rodeiam, formando assim a sua nova identidade.

A seguinte passagem serve para nos mostrar que ele tem consciência das adversidades da vida e do caminho complexo que precisa percorrer: "O meu corpo, no entanto, está doente. Não sei ainda como conviver com este calor úmido do Rio de Janeiro e com as pos- 
sibilidades (magníficas em outra ocasião) de um caminhar sem rotas marcadas, como este que é propiciado pela liberdade numa grande cidade" (p. 72).

Subjetivamente, a identidade construída no percurso da obra se encontra mascarada pelo véu da incerteza, da dúvida e da insegurança, visto que não se pode identificar quem é esse narrador/personagem. Ele nos tenta convencer de que quem está narrando é o próprio Graciliano, sendo este mais um ponto de contradição entre a realidade e a ficção.

É essa espécie de fingimento da verdade que leva o leitor a acreditar na existência do que está narrando, por isso sua identidade nunca é definida, pois não se pode definir a identidade de algo ou alguém que possivelmente não exista.

A todo tempo na obra Silviano reforça a questão da ficção, como se quisesse dizer que tudo quanto narra pode ou não ser verdade, como se pode observar na passagem: "Esforçome para não fazer ficção a partir dos acontecimentos que narro neste diário" (p. 97).

Outro ponto relacionado à questão da identidade nessa obra diz respeito à liberdade de que ele tanto fala. Na verdade, Silviano parece querer mostrar que a construção da identidade depende dessa liberdade, sem necessariamente o apoio de ninguém. Vejamos mais uma passagem do texto que nos comprova tal ideia: “- Para se libertar, é preciso jogar fora as muletas. Libertar-se para mim, é poder caminhar sozinho. Sozinho é que me revolto contra a injustiça humana. Não tem por que meter um amigo numa revolta que, no fundo é só minha” (p. 108).

Como se pode notar, Silviano procura no percorrer de sua narrativa confundir o leitor, de modo que este não consiga saber em que terreno está pisando. Deixa para esse leitor a responsabilidade de apontar quem está narrando os fatos, sem saber na verdade quem o faz. Compete também ao leitor a responsabilidade de descobrir que tipo de identidade é construída na obra.

Em mais um trecho da obra, é possível observar como ele deixa para o leitor essa função: “Assim, como o escritor se interessa pelo alargamento das suas fronteiras linguísticas, também o leitor tem de trabalhar nesse sentido se quiser acompanhar o romancista lendo a sua obra. [...] O discurso ficcional não tem a obrigação de seguir o circuito a que chamo de jornalístico (de semelhante para semelhantes)" (p. 116).

Consequentemente é esse jogo de segredos que faz da obra de Silviano uma grande obra dentro do panorama cultural brasileiro. Deixar para o leitor a função de descobrir esses segredos, apenas lhe dando pistas é uma forma de mostrar a complexidade da obra dentro da realidade em que se insere.

Não é à toa que as barreiras da realidade/ficção são quebradas e questionadas, pois o possível narrador/personagem está à procura de uma liberdade que ainda não encontrou e, é nessa liberdade que talvez possa encontrar sua verdadeira identidade.

Para ele, liberdade significa muito mais do que abrir uma simples porta da prisão, é ir além do pensamento, das palavras e das coisas que o cercam, sempre em busca de respostas que serão construídas e não prontas ou dadas de graça. Como se pode ver:

Não é conseguindo que se abram as portas da prisão que se chega mais depressa à liberdade. É não deixando que as pessoas mais chegadas venham correndo fechá -la de novo. [...] O problema para mim foi sempre o de enxergar, primeiro a chave 
da cela na mão da pessoa com quem ia conversar. Antes que fizesse uso da chave, lançava-me contra ela impetuosamente, arrebatando-a. Assim, fui evitando que as portas que transpunham no cotidiano fossem fechadas. (p. 145).

Ainda em se tratando do processo de construção da identidade na obra em questão, é preciso salientar que esta é vista como contraditória, uma vez que é formada ao longo do tempo pelos processos inconscientes e por isso, está sempre incompleta e em perfeito estado de transformação (HALL, 2006).

\section{CONCLUSÃO}

Aqui, o que encontramos é um indivíduo metamorfoseado que tenta convencer o leitor da veracidade dos fatos, sendo dessa forma uma identidade mascarada, marcada pela quebra de fronteiras entre a realidade e a ficção, o que confunde ainda mais o leitor.

É por essas e outras ideias presentes no texto que podemos reforçar a complexidade da obra de Silviano, tendo em vista os fatos narrados e sua relação com o mundo exterior.

A noção de que construímos nossa identidade através de sentidos construídos na completa relação com o outro e com a sociedade é uma das marcas encontradas na obra, pois o possível narrador/personagem se esconde por trás de uma máscara, no sentido de mostrar essa relação identidade/realidade/ficção.

Enfim, esperamos que nossas reflexões possam servir de base para outras possíveis leituras acerca da obra, considerando a heterogeneidade do texto literário e a capacidade crítica de cada leitor.

Por isso, nossa viagem somente dá uma pausa, no sentido de que a obra nos permite outras interpretações, sempre nos direcionando para a compreensão dos dilemas e contradições vividos em sociedade e sua relação com a literatura.

\section{REFERÊNCIAS}

HALL, S. A identidade cultural na pós-modernidade. Tradução Tomaz T. da Silva e Guacira L. Louro. $11^{\mathrm{a}}$ ed. Rio de Janeiro: DP\&A, 2006.

HUTCHEON, L. Descentralizando o pós-moderno: o ex-cêntrico. In: Poéticas do pósmodernismo: história, teoria e ficção. Rio de Janeiro: Imago, 1991.

MANGADELLI FERNANDES, G. Pós-moderno. In: FIGUEIREDO, E. (Org.) Conceitos de Literatura e Cultura. Juiz de Fora: UFJF, 2005.

SANTIAGO, S. Em Liberdade: uma ficção de Silviano Santiago. Rio de Janeiro: Paz e Terra, 1981. 